\title{
News Antibiotic Innovation Crisis
}

\section{Lopez-Tris CJ ${ }^{1}$ and Lopez-Tricas JM${ }^{2 *}$}

${ }^{1}$ Economist, Spain

${ }^{2}$ Hospital Pharmacist, Spain

*Corresponding author: Jose Manuel Lopez Tricas, Hospital Pharmacist, Zaragoza, Spain, Email: tricastriszar@telefonica.net

\section{Opinion}

There is a growing and justified concern in the pharmaceutical field for what can be called an innovation crisis in the development of novel antibiotics. The issue has transcended the health field, having been debated at a meeting of the World Economic Forum.

The World Health Organization has warned that we may find ourselves in what it has defined as a "post-antibiotic era". Deaths caused by germs resistant to all existing antibiotics are increasingly common.

Since the late 1980s, no new class of antibiotics has emerged. In the triennium 2011 to 2013, a very small number of new antibiotics were marketed, the smallest number of innovations since the 1940s, the start date of the antibiotic era. This trend continues today (2020).

The pharmaceutical industry has found an important business area in immunological pharmacology and gene therapy with novel and profitable drugs. Today pharmaceutical progress is directed towards the search for individualized treatments for diseases with a high prevalence such as cancer, hepatitis, or the development of new vaccines. However, this approach does not contribute significantly to raising public health standards. For this purpose, antibiotics and, increasingly, also antivirals, are a first-rate strategy.

An increasing number of antibiotics are withdrawn each year from the market due to the emergence of resistant germs. The pharmaceutical antibiotic arsenal currently consists of approximately 96 molecules, 17 fewer than those around the turn of the century.

Antibiotic research faces a bleak future: the costs of developing new drugs for highly prevalent diseases increase steadily while the benefits continue to decrease. According to experts from the American pharmaceutical multinational Eli
Lilly, the estimated cost of developing a new drug is around 1.8 trillion dollars, and the probability of not recovering the investment continues to increase.

Antibiotics are drugs with significant positive social external effects, but often relatively low private benefits [1], "market forces" not being sufficient forces for their investment. Unlike drugs for diseases that require longterm treatment, antibiotics are used for short time intervals, usually a few days. In addition to this situation, its prescription is often restricted to avoid the appearance of resistance, and the exclusivity period given by a patent license is often not long enough to make the initial investment profitable. The socalled "classic drugs" lose $80 \%$ of their market share within 1 year after the patent expiration. On the other hand, biological medicines have an "additional protection" derived from the difficulty of manufacturing generic biosimilar versions and homologating these to the original medicine.

As a result, biotechnological pharmaceutical companies have focused excessively on personalized therapies, many of them targeting so-called "rare diseases." Drugs for these diseases are called "orphan drugs" in pharmaceutical parlance. Of all the novel drugs licensed in recent years, 70\% were intended for diseases that afflict less than $1 \%$ of the population.

A crucial question is: how can the development of antibiotics be incentivized? The patent protection system has lonely been considered a valid instrument for that purpose. However, given the resistance to these drugs that is created over time, longer market exclusivity will likely fail as a solution.

As it has been mentioned, the characteristics of the antibiotics would justify determined public support. However, in the USA the public financial support remains 
stagnated [2]. A matter of debate is how that support should be conveyed.

The research process for antibiotics could be separated into two phases. The first one, the basic research, is a sort of a "black box" with uncertain results, and often, objectives. The second one, the clinical trial phase, is objective-oriented, and mostly privately funded. An effective funding policy ought to be based on strong public-private collaboration and aimed to cover the gaps that may arise between the different stages of the research and development process, to prevent promising projects to be abandoned [2].

Two novel strategies proposed are the adoption of Market Entry Rewards (MER) and Options Market for Antibiotics (OMA) [3]. MER is a direct payment mechanism that rewards the development of a certain antibiotic in a certain strategic area, with the requirements of not using the drug excessively. It is of utmost importance to mention that, due to the gigantic amount that these rewards will need to consist of they will necessarily have to be developed through international collaboration. On the other hand, OMAs are conformed of an option sale operation during the drug development process. In this way, a governmental or non-governmental organization, by acquiring the option, guarantees its capacity to be able to buy a certain volume of the product at a lower price than the market, without having to worry about additional costs of the production process. On the other hand, the pharmaceutical firm has access to new funding at crucial moments in the antibiotic development process.

Throughout the $20^{\text {th }}$ century, antibiotics have been a major driver of socio-economic progress. However, the proliferation of resistant pathogens is a serious threat to this trend [4]. The war against pathogens we are striving to immunize to is an endless one, and our most effective weapon has been, and continues to be, pharmaceutical research [5].

\section{References}

1. Simoens S (2010) Health Economics of Antibiotics. Pharmaceuticals 3(5): 1348-1359.

2. Kevin O, Powers JH (2015) Repairing The Broken Market For Antibiotic Innovation. Health Affairs 34(2): 277-285.

3. Christine A, Findlay D, SavicM, Carmeli Y, Gyssens I, et al. (2018) Revitalizing the antibiotic pipeline. DRIVE-AB, Innovative Medicines Initiative, pp: 1-12.

4. Renwick M, Mossiales E (2018) What are the economic barriers of antibiotic R\&D and how can we overcome them?. Expert Opinion on Drug Discovery 13(10): 889892.

5. Malik B, Bhattacharyya S (2019) Antibiotic drugresistance as a complex system driven by socio-economic growth and antibiotic misuse. Nature Research 9: 9788.

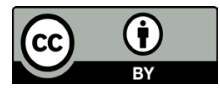

